\title{
Comparison between Modified MPC and DTC Control Method for Permanent Magnet Synchronous Motor
}

\author{
Huanyu $\mathrm{Li}^{i^{*}}$, Miao Lit ${ }^{1}$, Chenhong Zheng ${ }^{2}$ and Bingqian Chen ${ }^{2}$ \\ ${ }^{1}$ School of Electrical Engineering and Telecommunications, University of New South Wales, Australia \\ ${ }^{2}$ State Grid Fujian Power Economic Research Institute, China
}

\begin{abstract}
Direct torque control (DTC) and model predictive control (MPC) are widely used in the control of permanent magnet synchronous motor (PMSM). However, DTC for PMSM can cause large torque ripples and flux ripples, high harmonic distortion of the stator current, and high acoustic noises. Compared to DTC, MPC considers all possible switching states which can reduce the ripples of torque and flux. MPC with one-step delay compensation for PMSM and DTC with one-step delay compensation and two hysteresis comparators for PMSM have been proposed to solve some drawbacks of these two controllers. This paper makes a detailed comparison between these two improved control methods through Simulink and hardware experiments results to analyse the four indicators- torque ripple, flux ripple, transient time and THD of inverter current.
\end{abstract}

\section{Introduction}

Permanent magnet synchronous motor (PMSM) has widely used in industrial markets with the advantages of high efficiency, high reliability, high power density, high power factor, and high torque to current ratio with small size [1]. The high-performance control algorithm is highly required to meet this requirement. In 1997, the direct torque control (DTC) was applied to permanent magnet drive [2-3]. Compared to historical control methods, such as vector control and field-oriented control, DTC has a fast-dynamic torque response, and it is insensitive to motor's parameters except stator resistance. However, conventional DTC still has some drawbacks, such as large torque and flux ripples, high current harmonic distortion, and high sampling frequency due to hysteresis-based scheme.

In order to overcome these disadvantages, model predictive control (MPC) is introduced to PMSM drive system. Although the theory of it was raised in the 1970, MPC was applied for PMSM in last decade [4-6]. That is because the limitation of the hardware, such as slow calculation speed and low sampling frequency. This paper gives the details of modified DTC algorithms for PMSM and modified MPC algorithms for PMSM and compares the performance of both methods in simulation and experiment respectively.

The paper is divided into six sections. the mathematical model of PMSM is introduced in the section 2. the details of DTC algorithm and MPC algorithm for PMSM are described in section 3 and section 4 respectively. Section 5 shows the Simulink results of both methods, and the comparison results between two methods on the hardware result. Conclusions are shown in section 6.

\section{Mathematical model of PMSM}

Mathematical models of PMSM in ABC axis, d-q axis, and $\alpha-\beta$ axis respectively are shown in this section. In addition, the space vector principle is introduced.

\subsection{Space vector principle}

This section gives the relationship between the inverter switching states and the output voltage. The principle diagram used in this paper are shown in figure 1.

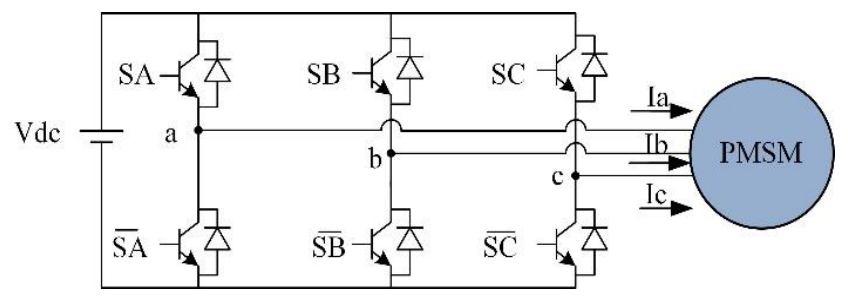

Fig. 1. Three-phase inverter

Switches SA, SB, SC and $\overline{\mathrm{SA}}, \overline{\mathrm{SB}}, \overline{\mathrm{SC}}$ are mutex. $\mathrm{S}_{1}$, $S_{2}$, and $S_{3}$ are defined as the following formula shows:

$$
\begin{aligned}
S_{1} & = \begin{cases}1 & \text { if SA on and } \overline{\mathrm{SA}} \text { off } \\
0 & \text { if SA off and } \overline{\mathrm{SA}} \text { on }\end{cases} \\
S_{2} & = \begin{cases}1 & \text { if } \mathrm{SB} \text { on and } \overline{\mathrm{SB}} \text { off } \\
0 & \text { if SB off and } \overline{\mathrm{SB}} \text { on }\end{cases} \\
S_{3} & = \begin{cases}1 & \text { if SC on and } \overline{\mathrm{SC}} \text { off } \\
0 & \text { if SC off and } \overline{\mathrm{SC}} \text { on }\end{cases}
\end{aligned}
$$

The output voltage $V_{\text {out }}$ is shown in formula (1)

$$
V_{\text {out }}=\frac{2}{3} V_{d c}\left(S_{1}+\boldsymbol{a} S_{2}+\boldsymbol{a}^{2} S_{3}\right)
$$

\footnotetext{
Corresponding author: lihuanyu1024@ outlook.com
} 
Where $V_{\text {out }}$ is the output voltage, $\boldsymbol{a}=e^{j \frac{2 \pi}{3}}$ is the $120^{\circ}$ shift between each phase. According to the equation (1), the voltage vector can be mapped into the complex plane, which is shown in figure 2 .

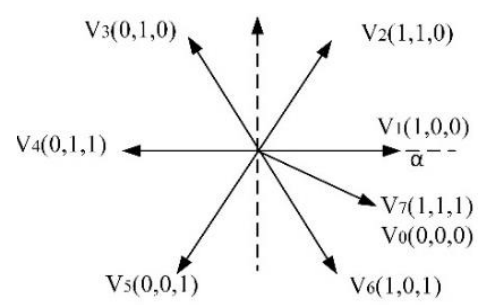

Fig. 2. Voltage vectors in complex plan

\subsection{PMSM equations in A-B-C Axis}

In three-phase static coordinate, $\mathrm{A}-\mathrm{B}-\mathrm{C}$, the stator voltage and flux can be presented as formula (2) shows

$$
\begin{gathered}
V_{s}=R_{s} i_{s}+\frac{d \Psi_{s}}{d t} \\
\Psi_{s}=L_{s} i_{s}+\Psi_{f} e^{j \theta_{r}}
\end{gathered}
$$

Where, $V_{s}$ and $I_{s}$ are the stator voltage and current respectively. $R_{S}$ refers to the stator resistance. $\Psi_{S}$ is the stator flux linkage, which is produced by rotor magnets and self-flux. $\mathrm{L}_{\mathrm{s}}$ stands for stator self-inductance, $\Psi_{\mathrm{f}}$ means magnet flux linkage, and $\theta_{\mathrm{r}}$ refers to rotor position. Then equations of stator voltage can be expressed as (4) shows. $\omega_{r}$ is the speed of the rotor.

$$
V_{s}=R_{s} i_{s}+L_{s} \frac{d i_{s}}{d t}+j \Psi_{f} \omega_{r} e^{j \theta_{r}}
$$

\subsection{PMSM equations in $d-q$ Axis}

Multiplying by $e^{-j \theta_{r}}$ on both sides of equation (4), the stator voltage can be presented in two-phase dynamic rotor d-q axis,

$$
V_{s}^{r}=R_{s} i_{s}^{r}+L_{s} \frac{d i_{s}^{r}}{d t}+j L_{s} \omega_{r} i_{s}^{r}+j \Psi_{f} \omega_{r}
$$

While $V_{s}{ }^{r}$ and $i_{s}{ }^{r}$ can be writen as follows: $V_{s}{ }^{r}=$ $V_{s} e^{-j \theta_{r}}=V_{s d}+j V_{s q}$, and $i_{s}^{r}=i_{s} e^{-j \theta_{r}}=i_{s d}+j i_{s q}$. Superscript $r$ indicates rotor coordinates. Use the new formation instead of the parameters in (5), the new expression in dq axis can be obtained as (6) shows,

$$
\begin{gathered}
V_{s d}=R_{s} i_{s d}+L_{d} \frac{d i_{s d}}{d t}-L_{q} \omega_{r} i_{s q} \\
V_{s q}=R_{s} i_{s q}+L_{q} \frac{d i_{s q}}{d t}+L_{d} \omega_{r} i_{s d}+\Psi_{f} \omega_{r}
\end{gathered}
$$

Using the same approach, the flux equation can be presented in d-q coordinate by

$$
\begin{gathered}
\Psi_{s d}=L_{d} i_{s d}+\Psi_{f} \\
\Psi_{s q}=L_{q} i_{s q}
\end{gathered}
$$

The electric torque can be presented as formula (9) shows:

$$
\begin{aligned}
T_{e} & =\frac{3}{2} p\left(\Psi_{s d} i_{s q}-\Psi_{s q} i_{s d}\right) \\
& =\frac{3}{2} p\left[\Psi_{f} i_{s q}+\left(L_{d}-L_{q}\right) i_{s d} i_{s q}\right]
\end{aligned}
$$

$p$ are the machine poles.

\subsection{PMSM equations in $\alpha-\beta$ Axis}

According to Clark Park transformation, the relationship between $d-q$ axis and $\alpha-\beta$ axis is shown below,

$$
\left[\begin{array}{l}
i_{\alpha} \\
i_{\beta}
\end{array}\right]=\left[\begin{array}{cc}
\cos \theta & -\sin \theta \\
\sin \theta & \cos \theta
\end{array}\right]\left[\begin{array}{l}
i_{d} \\
i_{q}
\end{array}\right]
$$

Therefore,

$$
T_{e}=\frac{3}{2} p\left(\Psi_{\alpha} i_{\beta}-\Psi_{\beta} i_{\alpha}\right)
$$

Where $T_{e}$ refers to the electric torque.

\section{The improved DTC for PMSM}

This section shows the DTC with two parallel one-step delay compensators for PMSM including voltage model and current model. The difference between voltage model and current model is the estimation equation [7]. Voltage model uses stator voltage equations in estimator, while current model uses current equations. The diagram of the improved DTC for PMSM is shown in the figure 3.

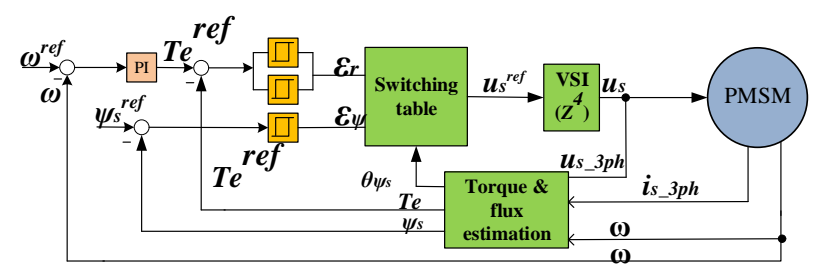

Fig. 3. DTC for PMSM

The switching table of DTC for PMSM is shown in the table 1 .

Table 1. Switching Table of DTC for PMSM

\begin{tabular}{|c|c|c|c|c|c|c|c|}
\hline \multirow{2}{*}{$\Delta \Psi$} & \multirow{2}{*}{$\Delta T_{e}$} & \multicolumn{7}{|c|}{$\theta_{i}$} \\
\cline { 3 - 8 } & & $\theta_{1}$ & $\theta_{2}$ & $\theta_{3}$ & $\theta_{4}$ & $\theta_{5}$ & $\theta_{6}$ \\
\hline \multirow{3}{*}{1} & 1 & $\mathrm{~V}_{2}$ & $\mathrm{~V}_{3}$ & $\mathrm{~V}_{4}$ & $\mathrm{~V}_{5}$ & $\mathrm{~V}_{6}$ & $\mathrm{~V}_{1}$ \\
\cline { 2 - 8 } & 0 & $\mathrm{~V}_{0}$ & $\mathrm{~V}_{7}$ & $\mathrm{~V}_{0}$ & $\mathrm{~V}_{7}$ & $\mathrm{~V}_{0}$ & $\mathrm{~V}_{7}$ \\
\cline { 2 - 8 } & -1 & $\mathrm{~V}_{6}$ & $\mathrm{~V}_{1}$ & $\mathrm{~V}_{2}$ & $\mathrm{~V}_{3}$ & $\mathrm{~V}_{4}$ & $\mathrm{~V}_{5}$ \\
\hline \multirow{3}{*}{0} & 1 & $\mathrm{~V}_{3}$ & $\mathrm{~V}_{4}$ & $\mathrm{~V}_{5}$ & $\mathrm{~V}_{6}$ & $\mathrm{~V}_{1}$ & $\mathrm{~V}_{2}$ \\
\cline { 2 - 8 } & 0 & $\mathrm{~V}_{7}$ & $\mathrm{~V}_{0}$ & $\mathrm{~V}_{7}$ & $\mathrm{~V}_{0}$ & $\mathrm{~V}_{7}$ & $\mathrm{~V}_{0}$ \\
\cline { 2 - 8 } & -1 & $\mathrm{~V}_{5}$ & $\mathrm{~V}_{6}$ & $\mathrm{~V}_{1}$ & $\mathrm{~V}_{2}$ & $\mathrm{~V}_{3}$ & $\mathrm{~V}_{4}$ \\
\hline
\end{tabular}

Where, $\Delta \psi$ is the output of the flux hysteresis controller, $\Delta \mathrm{T}_{\mathrm{e}}$ is the output of the torque hysteresis controllers and $\theta_{i}$ is the angle between stator flux and $\alpha$ axis. $\theta_{i}, \mathrm{i}=1,2,3 \ldots 6$, equally divide the voltage vectors plate into six parts, and $-30^{\circ} \leqslant \theta_{1} \leqslant 30^{\circ}$. In this case, two hysteresis controllers are used to produce the reference value of torque. Therefore, the zero voltages, V0 and 
V7 are added to the switching table. By doing this, the performance can be improved. The relationship between stator flux and VSI voltage vector is shown in figure 4.

At the instant $\mathrm{t}$, the flux vector is shown by $\psi \mathrm{s}(\mathrm{t})$. If a voltage vector, $\mathrm{V} 3$, is applied to the stator at $\mathrm{T}_{\mathrm{s}}$ second, the stator flux will be changed to $\psi \mathrm{s}\left(\mathrm{t}+\mathrm{T}_{\mathrm{s}}\right)$ position.

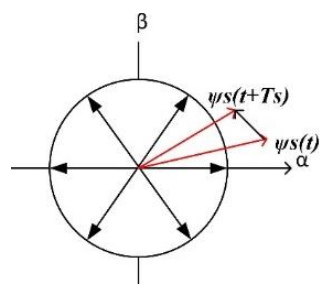

Fig. 4. Effect of voltage vector on stator flux

\subsection{DTC for PMSM based on voltage model}

Voltage model method refers that the stator flux is estimated by an integral equation where involves stator voltage. In this algorithm, the estimator should be designed by following equations.

$$
\begin{gathered}
\Psi_{\alpha}=\int\left(u_{\alpha}-R_{s} i_{\alpha}\right) d t \\
\Psi_{\beta}=\int\left(u_{\beta}-R_{s} i_{\beta}\right) d t \\
\left|\Psi_{s}\right|=\sqrt{\Psi_{\alpha}^{2}+\Psi_{\beta}^{2}}
\end{gathered}
$$

The electric torque is equal to

$$
T_{e}=\frac{3}{2} p\left(\Psi_{\alpha} i_{\beta}-\Psi_{\beta} i_{\alpha}\right)
$$

The advantage of this method is that the controller is insensitive to machine parameters. Only stator resistance has the influence on the controller.

\subsection{DTC for PMSM based on current model}

In current model, the estimation value is obtained by current equations showing below,

$$
\begin{gathered}
\Psi_{s d}=L_{d} i_{s d}+\Psi_{f} \\
\Psi_{s q}=L_{q} i_{s q} \\
\left|\Psi_{s}\right|=\sqrt{\Psi_{s d}^{2}+\Psi_{s q}^{2}}
\end{gathered}
$$

The electric torque is equal to

$$
T_{e}=\frac{3}{2} p\left[\Psi_{f} i_{s q}+\left(L_{d}-L_{q}\right) i_{s d} i_{s q}\right]
$$

In addition, the current transformation from A-B-C coordinate to $d-q$ coordinate is shown below, Where, $\theta$ is the rotor position.

$$
\left[\begin{array}{l}
i_{d} \\
i_{q} \\
i_{0}
\end{array}\right]=\frac{2}{3}\left[\begin{array}{ccc}
\cos \theta & \cos \left(\theta-\frac{2 \pi}{3}\right) & \cos \left(\theta+\frac{2 \pi}{3}\right) \\
-\sin \theta & -\sin \left(\theta-\frac{2 \pi}{3}\right) & -\sin \left(\theta+\frac{2 \pi}{3}\right) \\
\frac{1}{\sqrt{2}} & \frac{1}{\sqrt{2}} & \frac{1}{\sqrt{2}}
\end{array}\right]\left[\begin{array}{l}
i_{A} \\
i_{B} \\
i_{C}
\end{array}\right]
$$

The benefits of this method are that the integrator can be avoided. However, the rotor position is required. In addition, additional coordinate transformation, $d-q$ to $\alpha-\beta$, is required to calculate $\theta_{i} . \theta_{i}$ is the angle between stator flux and $\alpha$ axis, presented in table 1 .

\section{Modified MPC for PMSM}

This section shows the MPC with one-step delay compensator for PMSM.

\subsection{Theory of MPC for PMSM}

The basic idea of MPC for PMSM is using its mathematic model to predict the future behaviour of torque and flux in $\mathrm{d}-\mathrm{q}$ axis and minimize the cost-function to determine an optimum VSI output [8-10]. Figure 5 shows the modified MPC algorithm for PMSM.

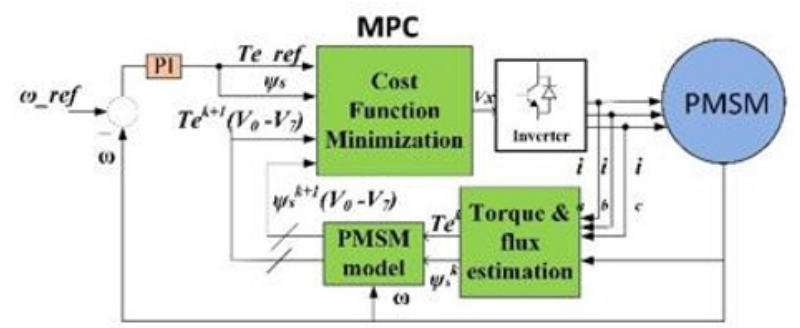

Fig. 5. MPC for PMSM

The estimator designed in this paper is based on current model which is as same as the method used in section3.2.According to following equations, the future current, $i_{s d}^{k+1}$ and $i_{s q}^{k+1}$, can be obtained. $T_{s}$ is the sampling time of controller.

$$
\begin{gathered}
\frac{d i_{s d}}{d t}=\left[V_{s d}-R_{s} i_{s d}+L_{q} \omega_{r} i_{s q}\right] / L_{d} \\
\frac{d i_{s q}}{d t}=\left[V_{s q}-R_{s} i_{s q}-L_{d} \omega_{r} i_{s d}-\Psi_{f} \omega_{r}\right] / L_{d} \\
i_{s d}^{k+1}=i_{s d}^{k}+\frac{d i_{s d}}{d t} T_{s} \\
i_{s q}^{k+1}=i_{s q}^{k}+\frac{d i_{s q}}{d t} T_{s}
\end{gathered}
$$

Then, the future behaviour of flux and torque can be calculated by following equations,

$$
\begin{gathered}
\Psi_{s d}^{k+1}=L_{d} i_{s d}^{k+1}+\Psi_{f} \\
\Psi_{s q}^{k+1}=L_{q} i_{s q}^{k+1} \\
T_{e}^{k+1}=\frac{3}{2} p\left[\Psi_{f} i_{s q}^{k+1}+\left(L_{d}-L_{q}\right) i_{s d}^{k+1} i_{s q}^{k+1}\right]
\end{gathered}
$$

Cost Function $=\left(\frac{\mathrm{T}_{\mathrm{ref}}-\mathrm{T}_{\mathrm{p}}^{\mathrm{k}+1}}{\mathrm{~T}_{\mathrm{ref}}}\right)^{2}+\mathrm{K} \cdot\left(\frac{\Psi_{\mathrm{ref}}-\Psi_{\mathrm{p}}^{\mathrm{k}+1}}{\Psi_{\mathrm{ref}}}\right)^{2}$

Where $T_{\text {ref }}$ and $\Psi_{\text {ref }}$ are torque and flux reference value, $T_{p}^{k+1}$ and $\Psi_{p}^{k+1}$ are predicted torque and flux value. $\mathrm{K}$ is a weighting factor used to adjust the ratio of torque and flux. The algorithm is shown in the figure 6.

\subsection{One step delay compensation}


Theory mentioned above assumes that data sampling, measurement, calculations, and voltage output are implemented at the same time. However, this assumption cannot be achieved in real world [11-13]. If the measured values are transferred into the controller at $k_{\text {th }}$ instant, the output will not be applied until $(k+1)$ th instant. This effect called one step delay. To compensate this effect, the one-step compensation based on model prediction is considered in this work. There are two kinds of the compensations being considered into one step delay compensation. One is rotor position, the other one is cost function.

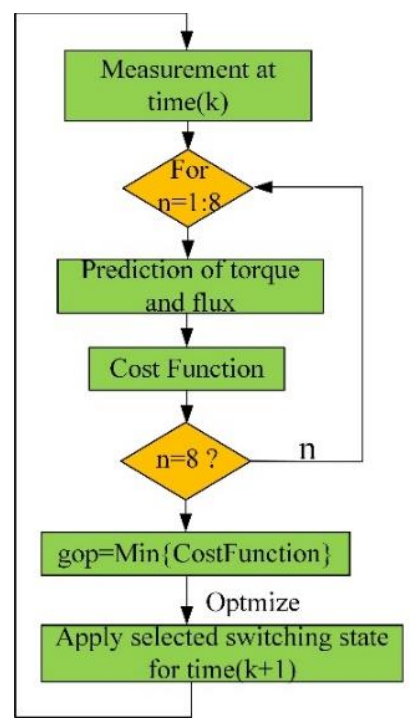

Fig. 6. The flow chart of MPC for PMSM

\subsubsection{Improvement of rotor position}

The rotor position will change after one sampling time. To avoid the influence of the one-step delay of rotor position, the rotor position in the calculation process should be used as the formula (30) shows.

$$
\theta^{k+1}=\theta^{k}+\omega T_{S}
$$

Where $\theta^{k+1}$ means the rotor position at time $\mathrm{k}+1, \theta^{k}$ means the rotor position at time $\mathrm{k}, \omega$ is the rotor speed, $T_{S}$ is the sampling time. Figure 7 shows the compensation of rotor position.

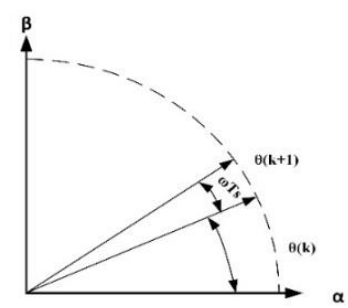

Fig. 7. Rotor position compensation

\subsubsection{Improvement of cost function}

To eliminate the effect of one-step delay, the cost function can be modified as formula (31) shows,
Cost Function $=\left(\frac{\mathrm{T}_{\mathrm{ref}}-\mathrm{T}_{\mathrm{p}}^{\mathrm{k}+2}}{\mathrm{~T}_{\mathrm{ref}}}\right)^{2}+\mathrm{K} \cdot\left(\frac{\Psi_{\mathrm{ref}}-\Psi_{\mathrm{p}}^{\mathrm{k}+2}}{\Psi_{\mathrm{ref}}}\right)^{2}$

\section{Experiment results}

The comparison has been conducted by Simulink and Hardware dSpace 1104 controller respectively. The parameters used are shown in Table 2.

\subsection{Simulation results}

Simulation results are shown in the figure 8 . From the figure $8(a)$, it is clear that MPC has the faster response time and smaller ripple than that of DTC. The Transient time for MPC is $1.054 \mathrm{~ms}$, while DTC takes $0.1 \mathrm{~ms}$ longer time to reach the steady state. During the steady state, the ripple in MPC is much smoother than that exists in DTC, which provides system more reliable operating environment.

It is obvious that in Figure 8(b), both flux in the MPC and DTC can follow the reference quite well indicating that the control method works within our expectation. However, the flux ripple in MPC is significantly smaller than ripples in DTC. In terms of THD, according to figure 9, the inverter current THD when using MPC is nearly 4 times less than the THD in DTC. That means, by using modified MPC method, the current has less harmonics distortion which avoids bringing other disturbance to the system. Table 3 gives the comparison details between DTC and MPC in simulation.

Table 2. Parameters for PMSM in Simulink and hardware

\begin{tabular}{|lc|c|}
\hline Number of pole pairs & $\mathrm{P}$ & 2 \\
\hline Stator resistance & $\mathrm{R}_{\mathrm{s}}$ & $18.6 \Omega$ \\
\hline Magnet flux linkage & $\Psi_{f}$ & $0.447 \mathrm{~Wb}$ \\
\hline d-axis inductance & $L_{d}$ & $0.3885 \mathrm{H}$ \\
\hline q-axis inductance & $L_{q}$ & $0.4755 \mathrm{H}$ \\
\hline Inverter phase voltage & $V_{d c}$ & $240 \mathrm{~V}$ \\
\hline Base speed & $\omega_{b}$ & $1,500 \mathrm{rpm}$ \\
\hline Crossover speed & $\omega_{c}$ & $2,400 \mathrm{rpm}$ \\
\hline Rated torque & $T_{b}$ & $1.95 \mathrm{Nm}$ \\
\hline Speed reference & $\omega_{r e f}$ & $500 \mathrm{rpm}$ \\
\hline Flux reference & $\Psi_{r e f}$ & $0.45 \mathrm{~Wb}$ \\
\hline
\end{tabular}

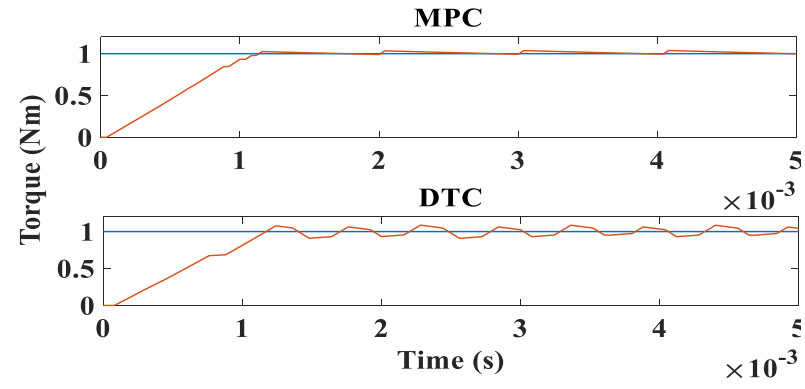

Fig. 8. (a) Torque comparison results 


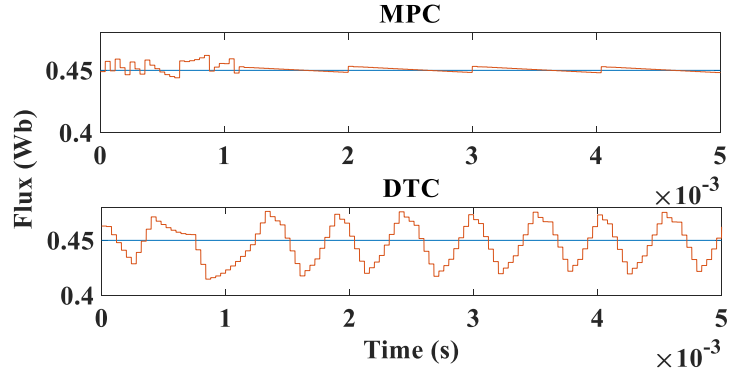

Fig. 8. (b) Flux comparison results

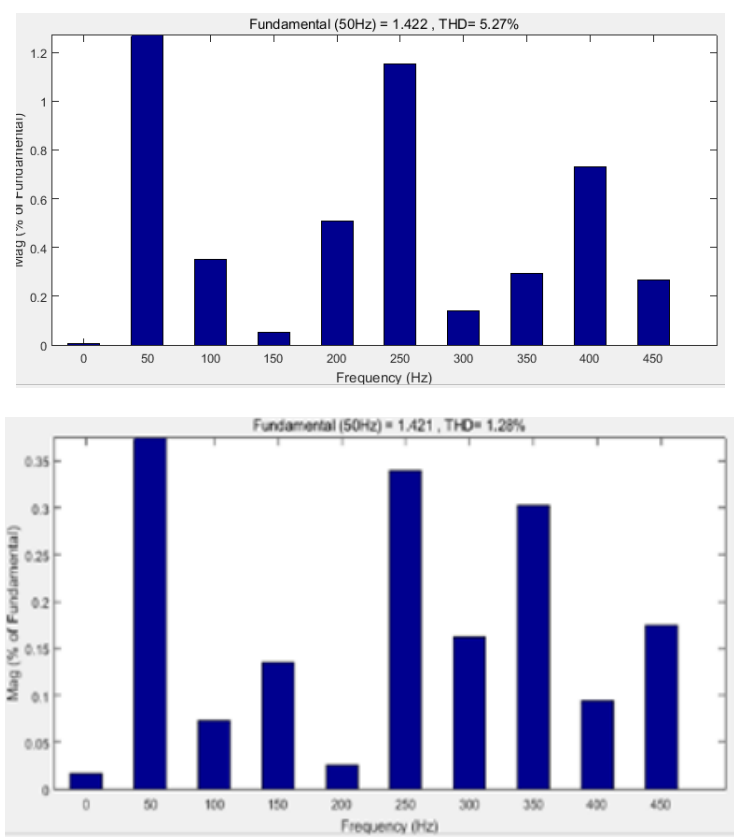

Fig. 9. (a) Inverter current THD for DTC (b) Inverter current THD for MPC

Table 3. Simulation Results

\begin{tabular}{|c|c|c|}
\hline & DTC & MPC \\
\hline Torque Ripple & $17.94 \%$ & $4.75 \%$ \\
\hline Flux Ripple & $13.67 \%$ & $3.73 \%$ \\
\hline Transient time & $1.169 \mathrm{~ms}$ & $1.054 \mathrm{~ms}$ \\
\hline THD & $5.27 \%$ & $1.28 \%$ \\
\hline
\end{tabular}

\subsection{Hardware experimental results}

The hardware experiment is conducted by using a dSPACE DS1104 control board, PMSM. The setup is shown in the figure 10 .The figure 11 shows that all the observe variables such as torque, flux and transient response can follow the reference, which means the control method can still work in the hardware. From the whole view, the MPC all have the better performance than those in DTC. However, the hardware data have large difference with those in Simulink experiment. The reason is that two systems have two different sampling time. Sampling time in Simulink is $40 \mathrm{e}-6 \mathrm{~s}$, while that in hardware is only $80 \mathrm{e}-6 \mathrm{~s}$. The limitation of the hardware is a big issue to the results. Table 4 shows comparison results in hardware platform.

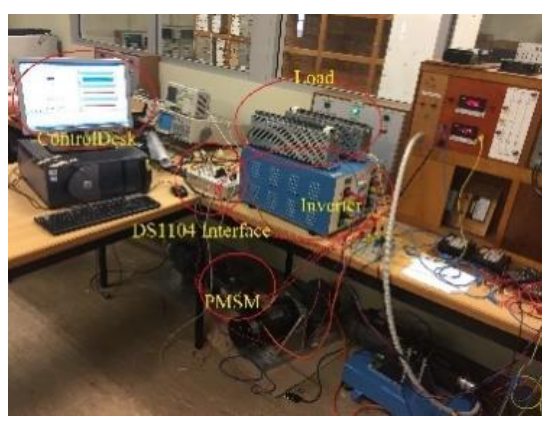

Fig.10. Hardware setup for MPC and DTC methods on PMSM

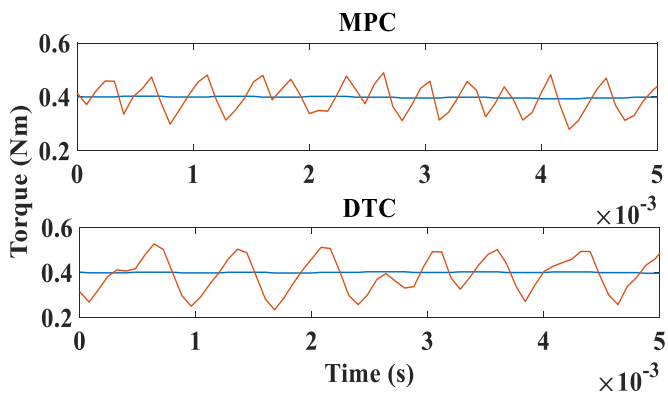

(a)

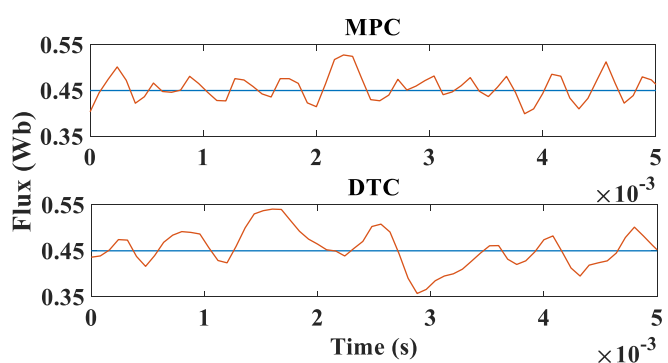

(b)

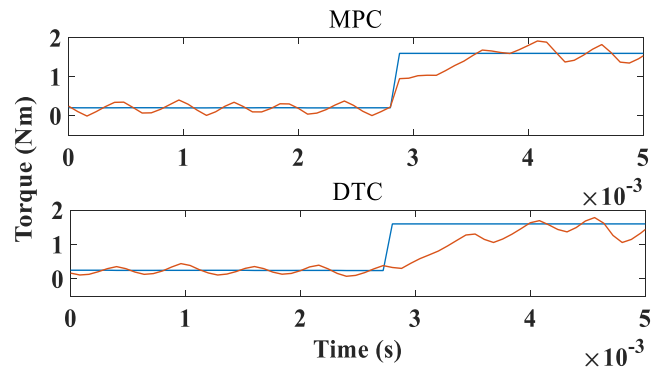

(c)

Fig. 11. (a) Torque comparison results (b) Flux comparison results

(c)Transient response

Table 4. The comparison Results between DTC and MPC

\begin{tabular}{|c|c|c|}
\hline & DTC & MPC \\
\hline Torque Ripple & $73.32 \%$ & $52.43 \%$ \\
\hline Flux Ripple & $40.77 \%$ & $28.52 \%$ \\
\hline Transient time & $1.631 \mathrm{~s}$ & $1.547 \mathrm{~s}$ \\
\hline THD & $8.73 \%$ & $2.06 \%$ \\
\hline
\end{tabular}

\section{Conclusion}

This paper mainly compares the performance of modified MPC and modified DTC for PMSM considering the effect of one-step delay on MPC algorithm. 
MPC method with one-step delay presents a better performance both in the steady-state and transient-state than DTC. One-step delay can influence the performance of MPC significantly. However, the disadvantages of MPC are computationally intensive and sensitive to system parameters.

\section{References}

1. T. M. Jahns, G. B. Kliman, and T. W. Neumann,, July 1986, "Interior permanent-magnet synchronous motors for adjustable-speed drives," IEEE Transactions on Industry Applications, vol. IA-22, no. 4, pp. 738-747

2. C. French and P. Acarnley, September/October 1996, "Direct torque control of permanent magnet drives," IEEE Transactions on Industry Applications, vol. 32, no. 5, pp. 1080-1088.

3. L. Tang, L. Zhong, M. Rahman, and Y. Hu, March 2003, "A novel direct torque control for interior permanent-magnet synchronous machine drive with low ripple in torque and flux: a speed-sensorless approach," IEEE Transactions on Industry Applications, vol. 39, no. 6, pp. 1748-1756.

4. H. Le-Huy, K. Slimani, and P. Viarouge, February 1994, "Analisis and implementation of a real-time predictive current controller for permanent-magnet synchronous servo drives," IEEE Transactions on Industrial Electronics, vol. 41, no. 1, pp. 110-117.

5. H.-T. Moon, H.-S. Kim, and M.-J. Youn, January 2003, "A discrete-time predictive current control for PMSM," IEEE Transactions on Power Electronics, vol. 18, no. 1, pp. 464-472.

6. E. Fuentes, J. Rodr'1guez, C. Silva, S. Diaz, and D. Quevedo, May 2009, "Speed control of a permanent magnet synchronous motor using predictive current control," in IEEE 6th International Power Electronics and Motion Control Conference, IPEMC '09, pp. 390-395.

7. F. Morel, X. Lin-Shi, J.-M. Retif, B. Allard, and C. Buttay, July 2009, "A comparative study of predictive current control schemes for a permanentmagnet synchronous machine drive," IEEE Transactions on Industrial Electronics, vol. 56, no. 7, pp. 2715-2728

8. E. Fuentes, C. Silva, D. Quevedo, and E. Silva, 2009,"Predictive speed control of a synchronous permanent magnet motor," in IEEE International Conference on Industrial Technology, ICIT 2009, 2009, pp. 1-6.

9. S. Bolognani, L. Tubiana, and M. Zigliotto, November/December 2003, "Extended Kalman filter tuning in sensorless PMSM drives," IEEE Transactions on Industry Applications, vol. 39, no. 6, pp. 1741-1747.

10. J. Rodr'1guez, J. Pontt, C. Silva et al. , February 2007, "Predictive current control of a voltage source inverter," IEEE Transactions on Industrial Electronics, vol. 54, no. 1, pp. 495-503.

11. P. Cort'es, J. Rodr'iguez, P. Antoniewicz, and M. Kazmierkowski, September 2008, "Direct power control of an AFE using predictive control," IEEE Transactions on Power Electronics, vol. 23, no. 5, pp. 2516-2523.

12. R. Vargas, J. Rodr'iguez, U. Ammann, and P. W. Wheeler, December 2008, "Predictive current control of an induction machine fed by a matrix converter with reactive power control," IEEE Transactions on Industrial Electronics, vol. 55, no. 12, pp. 4362-4371.

13. J. Rodr'iguez, J. Pontt, C. Silva et al ., February 2007, "Predictive current control of a voltage source inverter," IEEE Transactions on Industrial Electronics, vol. 54, no. 1, pp. 495-5 